\title{
BANGUNAN PENANGKAP SEDIMEN PADA SALURAN SEGI EMPAT (EXPERIMENTAL)
}

\author{
${ }^{1)}$ Nenny T. Karim ${ }^{2)}$ Rudi ${ }^{3)}$ Muhammad Rizal \\ ${ }^{1)}$ Universitas Muhammadiyah Makassar, Indonesia \\ Email:nennykarim@unismuh.ac.id \\ ${ }^{2)}$ Universitas Muhammadiyah Makassar, Indonesia \\ Email:iccankst@gmail.com \\ ${ }^{3)}$ Universitas Muhammadiyah Makassar, Indonesia \\ Email : rudicivil91@gmail.com
}

\begin{abstract}
Abstrak
penelitian ini secara umum bertujuan untuk mengetahui evektifitas bangunan penangkap sedimen pada saluran segi sedangkan secara khusus penelitian ini bertujuan untuk : 1) Mengetahui sifat aliran yang terjadi pada bangunan penangkap sedimen. 2) Mengetahui pengaruh tinggi muka air terhadap energi spesifik. 3)Mengetahui berapa besar angkutan sedimen dasar (Bed Load) pada bangunan penangkap sedimen dengan perhitungan secara langsung. 4)Mengetahui angkutan sedimen dasar pada banguan penangkap sedimen dengan menggunakan pendekatan empiris. 5) Mengetahui rumus pendekatan empiris untuk sedimen dasar yang hasil perhitungannya paling mendekati dengan hasil perhitungan secara langsung. Data yang kami ambil yaitu data primer dan sekunder, data primer adalah data yang diperoleh langsung dari simulasi model di laboratorium sedangkan data sekunder adalah data yang di peroleh dari literatur dan hasil penelitian yang sudah ada. Sedimentasi adalah suatu proses pengapungan, penggelindingan, penyeretan tanah hasil pecahan dari tubuh tanahnya. Sedimen adalah hasil proses erosi, baik berupa erosi permukaan, erosi parit, atau jenis erosi tanah lainnya.
\end{abstract}

Kata kunci; Sedimentasi, sedimen, bangunan penangkap sedimen.

\begin{abstract}
Abstrack
This study aims to determine the general building evektifitas sediment catcher in terms of channels whereas specifically, this study aims to: 1) Mengetahui flow properties occurs in the building sediment catcher. 2) Knowing the influence of water level of the specific energy. 3) Knowing how much sediment transport base (Bed Load) building sediment catcher with direct calculations. 4) Knowing the basic sediment transport in the building of sediment catcher using empirical approach. 5) Knowing formula empirical approach to sediment base the calculation results most closely with the calculated directly. The data we collect primary data and secondary, primary data is data obtained directly from the simulation model in the laboratory while secondary data is the data obtained from the literature and the results of existing research. Sedimentation is a flotation process, skidding, soil towage breakdown products of the soil body. Sediment is the result of erosion processes, either in the form of surface erosion, gully erosion, or other types of soil erosion.
\end{abstract}

Keywords: sedimentation, sediment, sediment catcher building.

\section{PENDAHULUAN}

Kontribusi prasarana dan sarana irigasi terhadap ketahanan pangan selama ini cukup besar, oleh karena itu ketersediaan air di lahan harus terpenuhi walaupun lahan tersebut berada jauh dari sumber air permukaan. Hal tersebut tidak terlepas dari usaha teknik irigasi yaitu memberikan air dengan kondisi tepat mutu, 
tepat ruang dan tepat waktu dengan cara yang efektif dan ekonomis (Sudjarwadi, 1990). sebanyak 84 persen (\%) produksi beras nasional bersumber dari daerah irigasi (Hasan, 2005). Untuk meningkatkan produksi pertanian selain dengan perbaikan mutu benih maka perlu juga diperhatikan peranan irigasi, untuk pendayagunaan air melalui sistem pengolahan yang baik, sehingga pemanfaatan air dapat dilakasanakan secara efektif dan efisien.Penumpukan sedimen pada saluran irigasi mempersingkat umur pelayanan jaringan irigasi karena pendangkalan dan penurunan kapasitas. Selanjutnya, penumpukan sedimen di petak sawah dan menaikkan permukaan sawah, sehingga mempersulit air untuk mencapai permukaan sawah dan mengairi sawah.

Partikel sedimen yang halus bahkan bisa menyumbat pori-pori tanah dan menghambat penyerapan air oleh tanaman (kuiper, 1989). Meskipun demikian tidak semua fraksi sedimen berpotensi merusak jaringan irigasi.

Berbagai upaya telah dilakukan untuk mengurangi angkutan sedimen yang dapat mengurangi evektifitas saluran irigasi. Salah satunya yang umum dilakukan adalah pembuatan bangunan penangkap sedimen (BPS). Meski demikian, sedimen masih saja tetap masuk ke dalam saluran irigasi dalam jumlah yang cukup besar. Sehingga dalam pengoperasian dan pemeliharaannya membutuhkan biaya yang cukup banyak untuk pengerukkan sedimen tersebut.

Tujuan penelitian ini adalah :

1) Untuk mengetahui sifat aliran yang terjadi pada BPS (bangunan penangkap sedimen).

2) Untuk mengetahui pengaruh tinggi muka air terhadap energi spesifik.

3 ) Untuk mengetahui berapa besar angkutan sedimen dasar (Bed Load) pada BPS (Bangunan Penangkap Sedimen) dengan perhitungan secara langsung.

4) Untuk mengetahui angkutan sedimen dasar pada BPS (Banguan Penangkap Sedimen) dengan menggunakan pendekatan empiris.

5) Untuk mengetahui rumus pendekatan empiris untuk sedimen dasar yang hasil perhitungannya paling mendekati dengan hasil perhitungan secara langsung.

Angkutan sedimen merupakan perpindahan tempat bahan sedimen granular (non kohesif) oleh air yang sedang mengalir searah aliran. Banyaknya angkutan sedimen $\mathrm{T}$ dapat ditentukan dari perpindahan tempat suatu sedimen yang melalui suatu tampang lintang selama periode waktu yang cukup. Lihat Gambar 1. T dinyatakan dalam (berat, massa, volume) tiap satuan waktu.

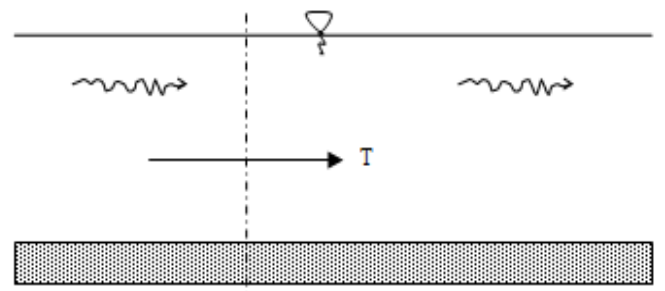

Gambar 1. Tampang panjang saluran dengan dasar granuler. (Mardjikoen, 1987) 
Laju sedimen yang terjadi dalam kondisi seimbang. Erosi, atau pengendapa, maka dapat ditentukan kuantitas sedimen yang terangkut daam proses tersebut. Proses sedimentasi di dasar saluran dapat dilihat pada gambar 4.

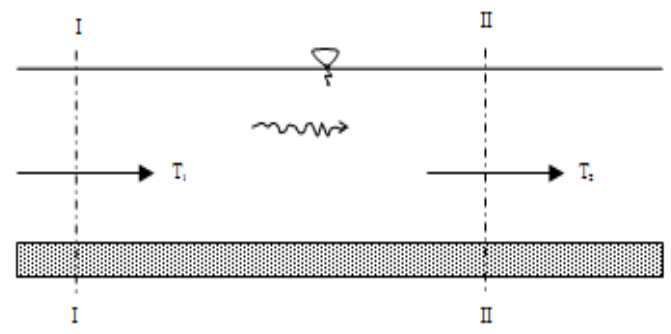

Gambar 2. Angkutan sedimen pada tampang panjang dengan dasar granuler.(Mardjikoen, 1987)

Partikel sedimen ukuran kecil seperti tanah liat dan debu dapat diangkut aliran air dalam bentuk terlarut (wash load). Sedang partikel yang lebih besar, antara lain, pasir cenderung bergerak dengan cara melompat. Partikel yang lebih besar dari pasir, misalnya kerikil bergerak dengan cara merayap atau menggelinding di dasar sungai.

Sedimentasi adalah suatu proses pengapungan, penggelindingan, penyeretan atau pemercikan jarah-jarah tanah hasil pemecahan dan telah terlepas dari satuan tubuh tanahnya, menempuh rentang jarak tertentu sampai tertahan di tempat pengendapan (Yang, 1996; Wulandari, 1999).

Kerusakan daerah aliran sungai menyebabkan meningkatnya angkutan sedimen yang terbawa aliran ke saluran irigasi. Jika kecepatan aliran ini rendah maka akan terjadi proses pengendapan di saluran irigasi tersebut. sedimentasi dapat dibedakan menjadi dua bagian yaitu (sumber :wordpress.com) :

a) Proses sedimentasi secara geologis : Sedimentasi secara geologis merupakan proses erosi tanah yang berjalan secara normal, artinya proses pengendapan yang berlangsung masih dalam batasbatas yang diperkenankan atau dalam keseimbangan alam dari proses degradasi dan agradasi pada perataan kulit bumi akibat pelapukan.

b) Proses sedimentasi yang dipercepat : Sedimentasi yang dipercepat merupakan proses terjadinya sedimentasi yang menyimpang dari proses secara geologi dan berlangsung dalam waktu yang cepat, bersifat merusak atau merugikan dan dapat mengganggu keseimbangan alam atau kelestarian lingkungan hidup. Kejadian tersebut biasanya disebabkan oleh kegiatan manusia dalam mengolah tanah. Cara mengolah tanah yang salah dapat menyebabkan erosi tanah dan sedimentasi yang tinggi.

\section{METODE PENELITIAN}

\section{Lokasi dan waktu Penelitian}

Penelitian dilaksanakan di labotatorium Fakulatas Teknik Sipil Universitas Muhammadiyah Makassar dengan rencana waktu penelitian selama 3 bulan yaitu dimulai bulan Maret sampai dengan bulan Juni, dimana pada bulan pertama yakni diawal bulan Maret merupakan kajian literatur, pada bulan kedua 
yakni bulan April adalah pembuatan Bangunan Penangkap Sedimen dan bulan ketiga yakni bulan Juni pengambilan data pada tahap pegelolaan data.

ProsedurPenelitian

Membuat model BPS (bangunan penangkap sedimen) dengan lebar dasar (B) :40 cm, Tinggi $(\mathrm{H}): 40 \mathrm{~cm}$, kemiringan dasar BPS $0.0229 \mathrm{~m} / \mathrm{m}$, dan panjang BPS (bangunan penangkap sedimen : $181 \mathrm{~cm}$. Melakukan pengaliran awal untuk mengetahui layak atau tidaknya BPS (bangunan penangkap sedimen) yang akan digunakan dalam pengaliran (Running kosong). Kalibrasi semua alat yang akan digunakan terutama alat pengukur kecepatan. Menimbang sedimen yang akan digunakan.

Sedimen dipadatkan sebelum dilakukan pengaliran. Kecepatan aliran diukur dengan current meter. Sedimen yang terperangkap di bangunan penangkap sedimen dikumpulkan diukur ketinggiannya. Sedimen dari bangunan penangkap sedimen dikumpulkan kemudian dikeringkan, lalu ditimbang. Percobaan dilakukan dengan debit dan waktu yang bervariasi.

Bagan alur penelitian

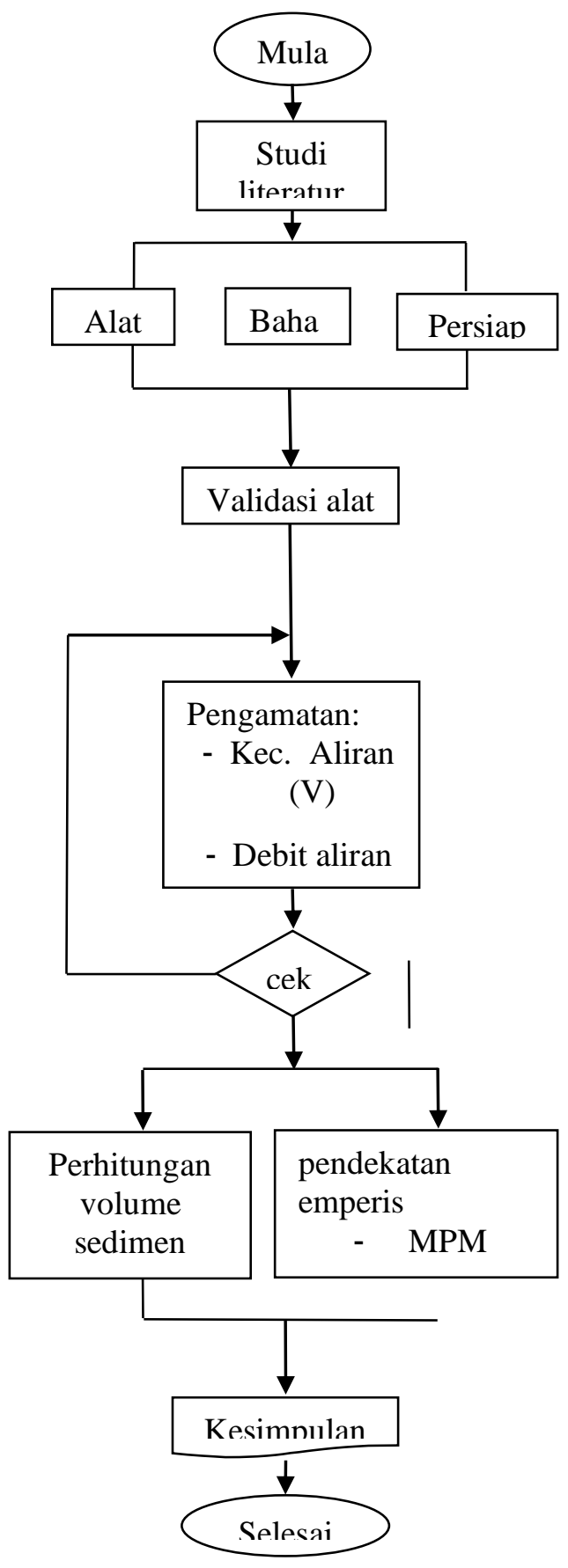

Gambar 3. Flowchart

\section{HASIL dan PEMBAHASAN}

Analisa Perhitungan Bilangan Froude.

Bilangan Froude ( $\mathrm{Fr}$ ) didefenisikan sebagai kecepatan rata-rata dibagi akar dari gravitasi dan kedalaman air.Jadi untuk mengetahui dan menetapkan jenis aliran 
yang terjadi dalam saluran pada saat proses pengaliran maka dapat dijabarkan atau di jelaskan berdasarkan dengan bilangan Froude (Fr), dimana :

$$
\operatorname{Fr}=\frac{V}{\sqrt{g h}}
$$

Hasil perhitungan bilangan Froude pada berbagai debit dan waktu yang digunakan dalam penelitian dapat dilihat pada tabel berikut :

Tabel 1. Perhitungan Bilangan Froude (Fr).

\begin{tabular}{|c|c|c||c|c||c|c|}
\hline \multirow{3}{*}{ No } & \multicolumn{7}{c|}{ Q1 (bukaan 1 cm) } \\
\cline { 2 - 7 } & \multicolumn{2}{|c|}{$\mathrm{t}=10$ menit } & \multicolumn{2}{c|}{$\mathrm{t}=15$ menit } & \multicolumn{1}{c|}{$\mathrm{t}=20$ menit } \\
\cline { 2 - 7 } & $\mathrm{v} 1$ & fr 1 & $\mathrm{v} 2$ & fr 2 & $\mathrm{v} 3$ & fr 3 \\
\hline \hline 1 & 1,03 & 1,66 & 1,02 & 1,68 & 1,00 & 1,60 \\
\hline 2 & 0,92 & 1,54 & 0,88 & 1,19 & 0,85 & 1,13 \\
\hline 3 & 0,80 & 1,17 & 0,76 & 0,89 & 0,72 & 0,79 \\
\hline 4 & 0,67 & 0,71 & 0,60 & 0,54 & 0,58 & 0,64 \\
\hline 5 & 0,55 & 0,46 & 0,45 & 0,36 & 0,42 & 0,37 \\
\hline 6 & 0,42 & 0,31 & 0,33 & 0,27 & 0,28 & 0,23 \\
\hline 7 & 0,30 & 0,20 & 0,20 & 0,14 & 0,16 & 0,12 \\
\hline
\end{tabular}

Sumber: Hasil Perhitungan

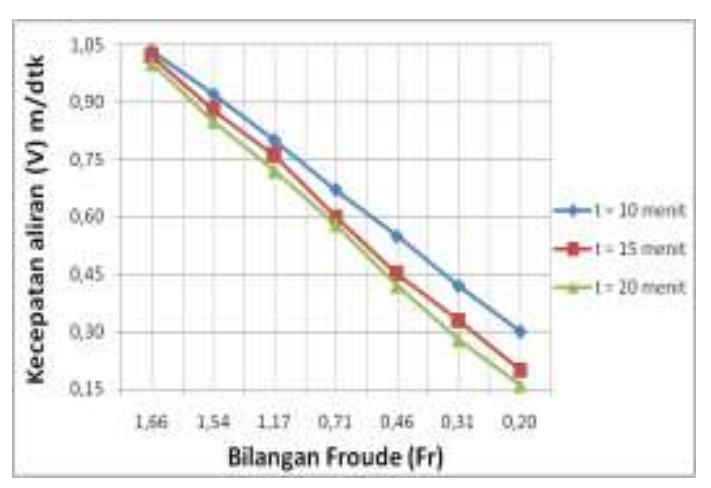

Gambar 4. Hubungan kecepatan (m/det) dan Bilangan Froude untuk debit pertama $\left(\mathrm{Q}_{1}\right)$

Tabel 2. Perhitungan Bilangan Froude (Fr).

\begin{tabular}{|c|c|c|c|c||c|c|}
\hline \multirow{2}{*}{ No } & \multicolumn{7}{|c|}{ Q2 (bukaan 2 cm) } \\
\cline { 2 - 7 } & \multicolumn{2}{|c|}{$\mathrm{t}=10$ menit } & \multicolumn{2}{c|}{$\mathrm{t}=15$ menit } & \multicolumn{2}{c|}{$\mathrm{t}=20$ menit } \\
\cline { 2 - 7 } & $\mathrm{v} 1$ & fr 1 & $\mathrm{v} \mathrm{2}$ & fr 2 & $\mathrm{v} \mathrm{3}$ & fr 3 \\
\hline \hline 1 & 1,23 & 1,76 & 1,20 & 1,71 & 1,18 & 1,78 \\
\hline 2 & 1,09 & 1,30 & 1,02 & 1,41 & 1,00 & 1,41 \\
\hline 3 & 0,96 & 1,02 & 0,88 & 1,00 & 0,87 & 1,27 \\
\hline 4 & 0,82 & 0,72 & 0,74 & 0,79 & 0,71 & 0,72 \\
\hline 5 & 0,68 & 0,54 & 0,58 & 0,44 & 0,55 & 0,44 \\
\hline 6 & 0,53 & 0,39 & 0,40 & 0,29 & 0,38 & 0,27 \\
\hline 7 & 0,35 & 0,23 & 0,23 & 0,15 & 0,18 & 0,11 \\
\hline
\end{tabular}

Sumber: Hasil Perhitungan

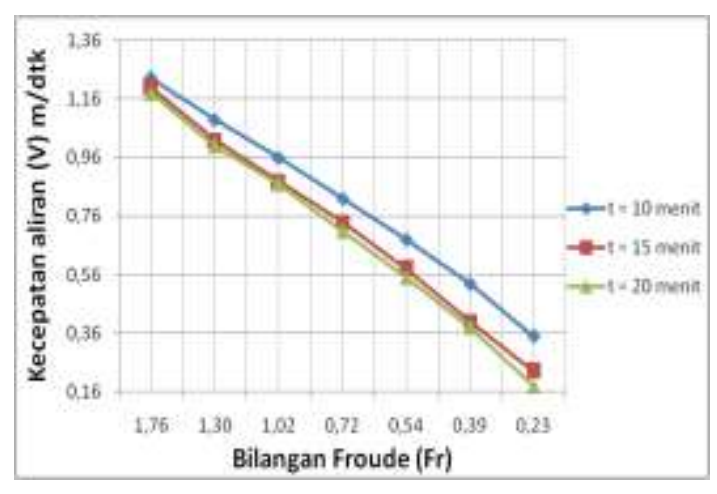

Gambar 5. Hubungan kecepatan (m/det) dan Bilangan Froude untuk debit kedua $\left(\mathrm{Q}_{2}\right)$

Tabel 3. Perhitungan Bilangan Froude (Fr).

\begin{tabular}{|c|c|c||c|c||c|c|}
\hline \multirow{3}{*}{ No } & \multicolumn{7}{c|}{ Q3 (bukaan 3 cm) } \\
\cline { 2 - 7 } & \multicolumn{1}{|c|}{$\mathrm{t}=10$ menit } & \multicolumn{2}{c|}{$\mathrm{t}=15$ menit } & \multicolumn{1}{c|}{$\mathrm{t}=20$ menit } \\
\cline { 2 - 7 } & $\mathrm{v} \mathrm{1}$ & fr 1 & $\mathrm{v} \mathrm{2}$ & fr 2 & $\mathrm{v} 3$ & fr 3 \\
\hline \hline 1 & 1,45 & 2,22 & 1,43 & 2,16 & 1,40 & 2,01 \\
\hline 2 & 1,26 & 1,85 & 1,24 & 1,62 & 1,20 & 1,43 \\
\hline 3 & 1,08 & 1,12 & 1,00 & 1,07 & 0,99 & 1,06 \\
\hline 4 & 0,89 & 0,85 & 0,80 & 0,77 & 0,77 & 0,79 \\
\hline 5 & 0,67 & 0,56 & 0,60 & 0,47 & 0,57 & 0,44 \\
\hline 6 & 0,48 & 0,36 & 0,39 & 0,27 & 0,36 & 0,25 \\
\hline 7 & 0,30 & 0,19 & 0,22 & 0,14 & 0,20 & 0,13 \\
\hline
\end{tabular}

Sumber: Hasil Perhitungan

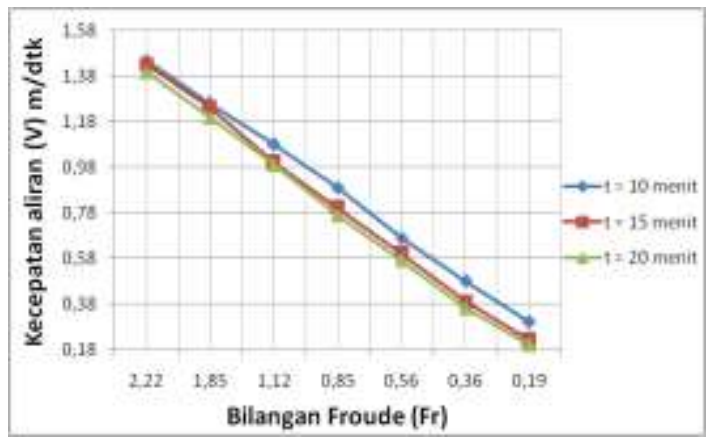

Gambar 6. Hubungan kecepatan (m/det) dan Bilangan Froude untuk debit kedua $\left(\mathrm{Q}_{2}\right)$

Dari hasil analisa untuk ketiga gambar diatas maka dapat di simpulkan bahwa semakin besar kecepatan aliran maka semakin tinggi angka Froudenya. Begitu pula sebaliknya semakin kecil kecepatan aliran maka semakin rendah pula bilangan Froudenya.

Analisa Bilangan Reynold. 
Keadaan atau perilaku aliran pada saluran terbuka pada dasarnya ditentukan oleh pengaruh kekentalan dan gravitasi. Pengaruh kekentalan aliran dapat bersifat laminar, turbulen dan peraliran. kekentalan relatif dapat dinyatakan dengan bilangan Reynold yang didefiniskan sebagai berikut:

$$
R e=\frac{\tilde{v} R}{\mu}
$$

Tabel 4. Perhitungan Bilangan Reynold $(\mathrm{Re})$.

\begin{tabular}{|c||c|c||c|c||c|c|}
\hline \multirow{3}{*}{ No } & \multicolumn{9}{|c||}{ Q1 (bukaan 1 cm) } \\
\cline { 2 - 7 } & \multicolumn{2}{|c|}{$\mathrm{t}=10$ menit } & \multicolumn{2}{c|}{$\mathrm{t}=15$ menit } & \multicolumn{2}{c|}{$\mathrm{t}=20$ menit } \\
\cline { 2 - 7 } & $\mathrm{v1}$ & Re 1 & $\mathrm{v} 2$ & Re 2 & $\mathrm{v3}$ & Re 3 \\
\hline \hline 1 & 1,03 & 44,207 & 1,02 & 260,1 & 1,00 & 246,0 \\
\hline 2 & 0,92 & 99,117 & 0,88 & 110,5 & 0,85 & 104,5 \\
\hline 3 & 0,80 & 65,909 & 0,76 & 110,5 & 0,72 & 104,5 \\
\hline 4 & 0,67 & 28,747 & 0,60 & 110,5 & 0,58 & 104,5 \\
\hline 5 & 0,55 & 14,573 & 0,45 & 110,5 & 0,42 & 104,5 \\
\hline 6 & 0,42 & 8,789 & 0,33 & 142,5 & 0,28 & 134,8 \\
\hline 7 & 0,30 & 4,935 & 0,20 & 142,5 & 0,16 & 134,8 \\
\hline
\end{tabular}

Sumber: Hasil Perhitungan

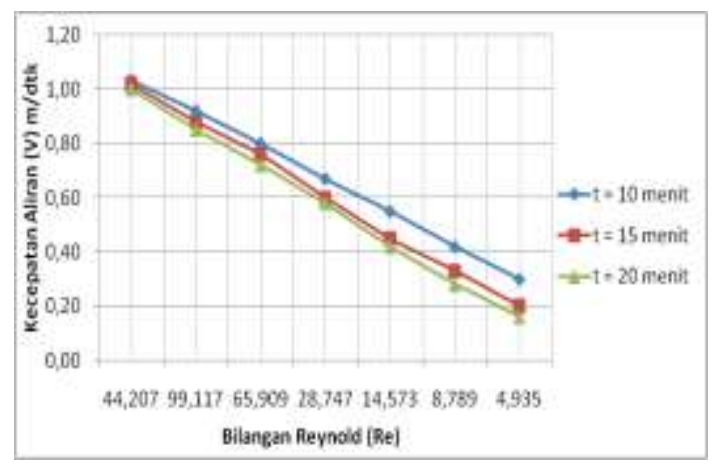

Gambar 7. Hubungan kecepatan aliran $(\mathrm{m} / \mathrm{det})$ dan Bilangan Reynold

Tabel 5. Perhitungan Bilangan Reynold (Re)

\begin{tabular}{|c|c|c||c|c||c|c|}
\hline \multirow{2}{*}{ No } & \multicolumn{9}{|c|}{ Q2 (bukaan 2 cm) } \\
\cline { 2 - 7 } & \multicolumn{2}{|c|}{$\mathrm{t}=10$ menit } & \multicolumn{2}{c|}{$\mathrm{t}=15$ menit } & \multicolumn{2}{c|}{$\mathrm{t}=20$ menit } \\
\cline { 2 - 7 } & $\mathrm{v} 1$ & $\mathrm{Re} 1$ & $\mathrm{v} 2$ & $\operatorname{Re} 2$ & $\mathrm{v} 3$ & $\mathrm{Re} 3$ \\
\hline \hline 1 & 1,23 & 347,2 & 1,20 & 309,8 & 1,18 & 298,7 \\
\hline 2 & 1,09 & 147,4 & 1,02 & 131,6 & 1,00 & 126,9 \\
\hline 3 & 0,96 & 147,4 & 0,88 & 131,6 & 0,87 & 126,9 \\
\hline 4 & 0,82 & 147,4 & 0,74 & 131,6 & 0,71 & 126,9 \\
\hline 5 & 0,68 & 147,4 & 0,58 & 131,6 & 0,55 & 126,9 \\
\hline 6 & 0,53 & 190,3 & 0,40 & 169,7 & 0,38 & 163,7 \\
\hline 7 & 0,35 & 190,3 & 0,23 & 169,7 & 0,18 & 163,7 \\
\hline \hline
\end{tabular}

Sumber: Hasil Perhitungan

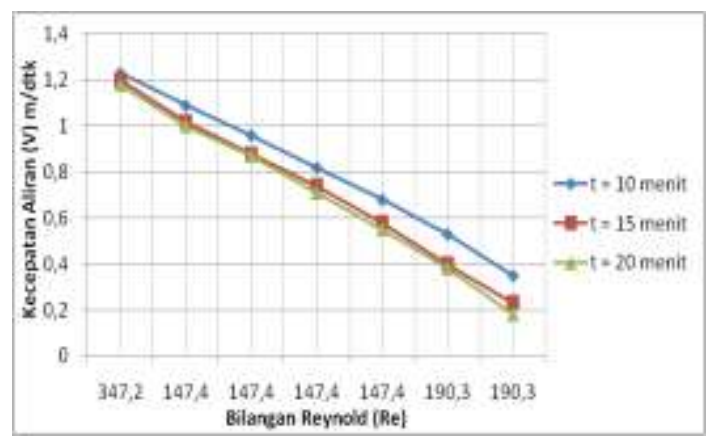

Gambar 8. Hubungan kecepatan aliran (m/det) dan Bilangan Reynold

Tabel 6. Perhitungan Bilangan Reynold (Re)

\begin{tabular}{|c|c|c|c|c|c|c|}
\hline \multirow{3}{*}{ No } & \multicolumn{6}{|c|}{ Q3 (bukaan $3 \mathrm{~cm}$ ) } \\
\hline & \multicolumn{2}{|c|}{$t=10$ menit } & \multicolumn{2}{|c|}{$t=15$ menit } & \multicolumn{2}{|c|}{$t=20$ menit } \\
\hline & V1 & $\operatorname{Re} 1$ & $\mathrm{~V} 2$ & $\operatorname{Re} 2$ & v3 & $\operatorname{Re} 3$ \\
\hline 1 & 1,45 & 376,0 & 1,43 & 348,6 & 1,40 & 336,8 \\
\hline 2 & 1,26 & 159,7 & 1,24 & 148,1 & 1,20 & 143,0 \\
\hline 3 & 1,08 & 159,7 & 1,00 & 148,1 & 0,99 & 143,0 \\
\hline 4 & 0,89 & 159,7 & 0,80 & 148,1 & 0,77 & 143,0 \\
\hline 5 & 0,67 & 159,7 & 0,60 & 148,1 & 0,57 & 143,0 \\
\hline 6 & 0,48 & 206,1 & 0,39 & 191,0 & 0,36 & 184,5 \\
\hline 7 & 0,30 & 206,1 & 0,22 & 191,0 & 0,20 & 184,5 \\
\hline
\end{tabular}

Sumber: Hasil Perhitungan

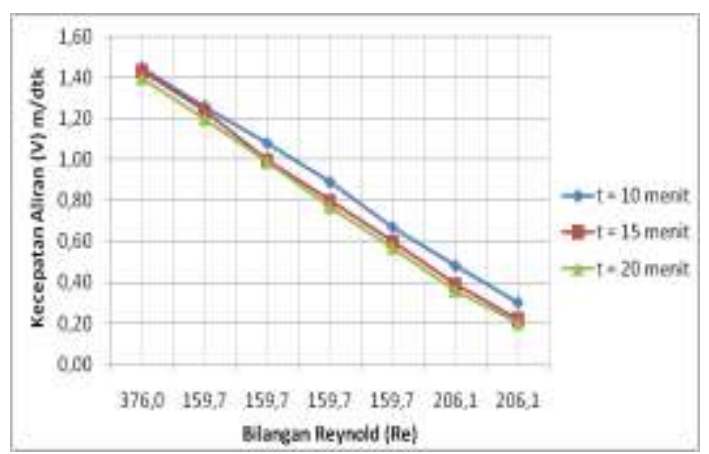

Gambar 9. Hubungan kecepatan aliran $(\mathrm{m} / \mathrm{det})$ dan Bilangan Reynold

Analisa Volume Angkutan Sedimen Dasar dengan Pendekatan Empiris.

1) Rumus Meyer-peter dan Muller

$$
\begin{aligned}
& \frac{\gamma \cdot R_{b}\left(K / K^{\prime}\right)^{\frac{3}{2}}}{D\left(\gamma_{s}-\gamma\right)} \\
& -0,047 \frac{1.0 .021(1)^{\frac{3}{2}}}{D\left(\gamma_{s}-\gamma\right)}-0,047
\end{aligned}
$$




$$
\begin{aligned}
=0,25 \sqrt[3]{\frac{1000}{9,81}} \frac{\left(q_{B}^{\prime}\right)^{3 / 2}}{0,0007(1444-1000)} \\
\quad 6,764121335-0,047 \\
=\frac{0,25.4,673}{0.003048948}\left(q_{B}^{\prime}\right)^{2 / 3} 6,764121335 \\
=383,1610011\left(q_{B}^{\prime}\right)^{3 / 2} \\
q_{B}^{\prime}=0,01753081^{3 / 2} \\
=0,002321148 \mathrm{~kg} / \mathrm{s} \\
q_{B}=q_{B}^{\prime} \frac{\gamma_{S}}{\left(\gamma_{S}-\gamma\right)} \\
q_{B}=0,00232115 \quad \frac{1444}{(0,444)}=0,007549
\end{aligned}
$$$$
\mathrm{kg} / \mathrm{s}
$$$$
Q_{B}=B \cdot q_{B}
$$$$
Q_{B}=0.371 .0,007549=0.002804 \mathrm{~kg} / \mathrm{s}
$$$$
\text { volume pengangkutan sedimen selama }
$$

10 menit (600 detik) adalah:

$$
\begin{array}{r}
\frac{0.002803899 \mathrm{~kg} / \text { detik }}{444 \mathrm{~m}^{3}} 600 \text { ditik } \\
=0.004 \mathrm{~kg} / \mathrm{m}^{3}
\end{array}
$$

Untuk perhitungan selanjutnya dengan variasi debit dan waktu dapat dilihat pada lampiran.

2) Rumus Schocklitsch

$$
\begin{aligned}
q_{B} & =2500 S^{3 / 2}\left(q-q_{c}\right) \\
q & =d \cdot U \\
& =(0,11265)(0,705) \\
& =0,07939 \mathrm{~m}^{3} /(\mathrm{det})(\mathrm{m}) \\
q_{C} & =\frac{(1,944) \cdot\left(10^{-5} \cdot D\right)}{S^{4 / 3}} \\
& =\frac{(1,944) \cdot\left(10^{-5} \cdot 0,0007\right)}{(0,0229)^{4 / 3}} \\
& =0,0000020907 \mathrm{~kg} / \mathrm{s} \\
q_{B}= & (2500)(0,0229)^{3 / 2} \\
& 0,07939-0,0000020907) \\
= & 0,6884699 \mathrm{~kg} / \mathrm{s} \\
Q_{B}= & \text { B. } q_{B}=(0,37)(0,688469908)
\end{aligned}
$$

$$
=0,255717395 \mathrm{~kg} / \mathrm{s}
$$

volume pengangkutan sedimen selama 10 menit (600 detik) adalah:

$$
\begin{aligned}
& =\frac{Q_{B}}{\left(\gamma_{s}-\gamma\right)} t \\
& =\frac{0,255717395 \mathrm{~kg} / \mathrm{s}}{(1444-1000) \mathrm{kg} / \mathrm{m}^{3}} 600 \mathrm{~s} \\
& =0.345564047 \mathrm{~m}^{3}
\end{aligned}
$$

Untuk perhitungan selanjutnya dengan variasi debit dan waktu dapat dilihat pada lampiran.

3) Rumus Kalinske

$\frac{q_{s}}{U^{*} D}=f\left(\frac{\tau_{c}}{\tau_{o}}\right)$

$\left(\frac{\tau_{c}}{\tau_{o}}\right)=\frac{0.37}{25.32}=0,015$, dari gambar didapat $\frac{q_{S}}{U^{*} D}=1.25$ (lihat Grafik persamaan beban alas Kalinske pada lampiran).

$$
\begin{aligned}
\frac{q_{s}}{U^{*} D} & =1.25 \\
q_{s} & =1.25\left(U^{*} D\right) \\
& =(1.25)(0,159133)(0,0007) \\
& =0,0001392 \mathrm{~kg} / \mathrm{s} \\
q_{B} & =q_{s} \cdot \gamma_{s}=(0,0001392)(1444) \\
& =0.2010642 \mathrm{~kg} / \mathrm{s} \\
Q_{B} & =B \cdot q_{B} \\
& =(0,37)(0,2010642) \\
& =0,07439 \mathrm{~kg} / \mathrm{s}
\end{aligned}
$$

volume pengangkutan sedimen selama 10 menit

$$
\begin{aligned}
& =\frac{Q_{B}}{\left(\gamma_{S}-\gamma\right)} t \\
& =\frac{0,07439}{(1444-1000) \mathrm{kg} / \mathrm{m}^{3}} 600 \mathrm{~s} \\
& =0.10053 \mathrm{~m}^{3}
\end{aligned}
$$

Untuk perhitungan selanjutnya dengan variasi debit dan waktu dapat dilihat pada lampiran. 
Rekapitulasi Analisa Volume Angkutan Sedimen Dasar dan Pengendapan Dengan Pendekatan Empiris.

Tabel 7. Rakapitulasi analisa volume angkutan sedimen dasar dan Pengendapan dengan Pendekatan Empiris

\begin{tabular}{|c|c|c|c|c|c|c|c|c|}
\hline \multirow{3}{*}{ No } & \multirow{3}{*}{$\mathrm{h}$} & \multirow{3}{*}{ V } & \multirow{3}{*}{ Debit } & \multirow{3}{*}{ Waktu } & \multicolumn{3}{|c|}{ volume angkutan sedimen } & \multirow{2}{*}{\begin{tabular}{|c|} 
volume angkutan \\
sedimen \\
\end{tabular}} \\
\hline & & & & & Meyer-Peter & & & \\
\hline & & & & & dan Muller & & & perhitungan langsung \\
\hline 1 & 0,113 & 0,705 & \multirow{3}{*}{0,008} & 600 & 0,004 & 0,346 & 0,101 & 0,045 \\
\hline 2 & 0,115 & 0,588 & & 900 & 0,004 & 0,440 & 0,025 & 0,046 \\
\hline 3 & 0,104 & 0,600 & & 1200 & 0,006 & 0,202 & 0,034 & 0,048 \\
\hline 4 & 0,131 & 0,851 & \multirow{3}{*}{0,004} & 600 & 0,002 & 0,486 & 0,017 & 0,049 \\
\hline 5 & 0,127 & 0,730 & & 900 & 0,004 & 0,604 & 0,036 & 0,050 \\
\hline 6 & 0,124 & 0,180 & & 1200 & 0,006 & 0,193 & 0,036 & 0,051 \\
\hline 7 & 0,124 & 0,898 & \multirow{3}{*}{0,008} & 600 & 0,002 & 0,358 & 0,018 & 0,052 \\
\hline 8 & 0,133 & 0,722 & & 900 & 0,004 & 0,627 & 0,008 & 0,053 \\
\hline 9 & 0,135 & 0,703 & & 1200 & 0,004 & 0,823 & 0,039 & 0,053 \\
\hline
\end{tabular}

Sumber: Hasil Perhitungan

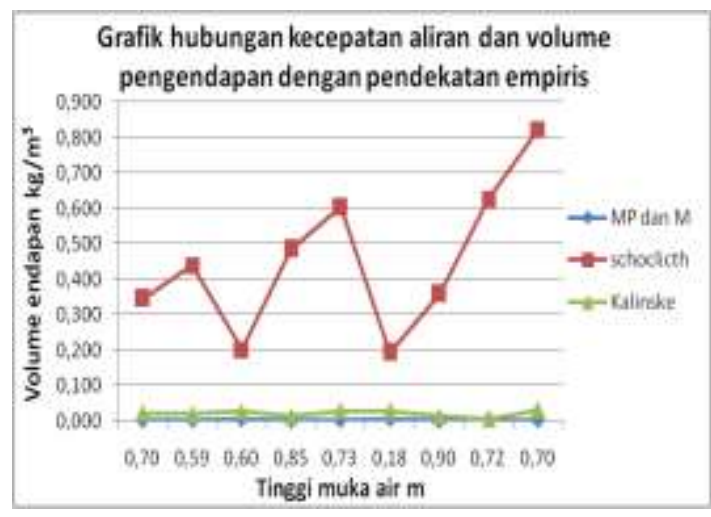

Gambar 10. Grafik antara perhitungan langsung dengan perhitungan pendekatan empiris.

\section{PENUTUP}

\section{Kesimpulan}

Berdasarkan hasil penelitian yang telah dilakukan, maka dapat disimpulkan bahwa : Dari hasil pengamatan sifat aliran setelah melalui sekat bercincin, maka aliran yang terjadi adalah aliran super kritis pada hulu
BPS (Bangunan Penangkap Sedimen) dan lambat laun berubah menjadi sub kritis pada sekat 5. Dari hasil analisa hubungan tinggi muka mata air dengan energi spesifik dapat diketahui bahwa semakin tinggi permukaan aliaran maka semakin tinggi pula energi spesifiknya. Volume angkutan sedimen dasar pada perhitungan tinggi endapan yang paling besar terjadi pada $\mathrm{Q}_{3}, \mathrm{t}=10$ menit dengan nilai $0,00319 \mathrm{~m}^{2}$ dan volume endapan yang paling rendah terjadi pada $\mathrm{Q}_{1}, \mathrm{t}=15$ menit dengan nilai $0,00164 \mathrm{~m}^{2}$. Volume angkutan sedimen dasar dengan pendekatan empiris yang paling besar adalah pendekatan Schocklitsch $\mathrm{Q}_{2}, \mathrm{t}=15$ menit dengan nilai $0,60360 \mathrm{~m}^{2}$ sedangkan volume endapan yang paling rendah terjadi pada pendekatan Meyer-Peter dan Muller untuk $\mathrm{Q}_{2}, \mathrm{t}=10$ menit dengan nilai $0,00402 \mathrm{~m}^{2}$.

Pendekatan empiris dari ketiga ahli yang paling mendekati dengan hasil perhitungan volume endapan pada saluran adalah pendekatan empiris Meyer-Peter dan Muller.

\section{Saran}

Dari pengamatan di dalam penelitian ini penulis memberikan saran-saran untuk peneitian lebih lanjut, yaitu : Penelitian tentang volume angkutan sedimen ini perlu dikembangkan lagi dengan menambahkan variasi debit. Untuk penelitian selanjutnya perlu dilakukan pengamatan untuk jenis sedimen yang lebih bervariasi dan spesifik.

\section{DAFTAR PUSTAKA}

Abdurrosyid, Jaji, 2006. Kajian Model Hidraulik Kantong Lumpur 
Bendung Colo Sukoharjo.

Adinegara, Subari.2014. Volume Angkutan Sedimen Dipengaruhi Oleh Aliran. Palembang

Alwi, afii achmad, 2004. Efektivitas

Bangunan Penangkap Sedimen

Pada Jaringan Irigasi.

Universitas Diponegoro.

Semarang

Asdak, C. 2014. Hidrolgi dan Pengolahan

Daerah Aliran Sungai. Gajah

Mada University Press,

Yogyakarta.

Hardiyatmo, christady hady. Mekanika Tanah. Gajah madah

Hanwar, Suhendrik dkk. 2007. Desain

Bangunan Penangkap Sedimen dengan Teknologi Baffle (sekat).

Herdianto, Revalin dkk. 2010. Kombinasi

Sekat dan Tanaman Air Untuk Optimasi Bangunan Penangkap Sedimen.

Karim, T Nenny.2010. Bahan Kuliah Angkutan Sedimen, Fakultas Teknik Sipil UNISMUH.Makassar

Kodoatie Robert J. (2002). Hidrolika Terapan (aliran pada saluran terbuka dan pipa). ANDI yokyakarta.

Samitra Azwar, 2013. Pengaruh Aliran Terhadap formasi Sedimen Dasar di Sungai Cikapundung di Bandung. Universitas Pendidikan Bandung Indonesia.
Sudirman Andi, 2004. Pengaruh Konsentrasi Pada Efesiensi Pengendapan Bangunan Penangkap Sedimen.

Wirosoedarmo, Ruslan dkk, 2011. Prilaku Sedimentasi dan Pengaruhnya Terhadap Kinerja Saluran Pada Jaringan Irigasi Waru-Turi Kanan Kediri. Fak. Teknologi Pertanian-Universitas Brawijaya. Malang. (http://google,diakses

Triatmodjo, Bambang (2008). Hidrolika II. Beta Offset. Yogyakarta.

Yang Chih Ted. (1996). Sediment Transport (theory and practice). Mc. Graw Hill International Edition Civil Engineering series.

Yang Chih Ted. (1996). Sediment Transport (theory and practice). Mc. Graw Hill International Edition Civil Engineering series. 